\title{
Cohesive Chains in the Transfiguration Narrative of Matthew 17:1-13
}

\author{
Justin R. Woods \\ McMaster Divinity College, Ontario, Canada \\ Email: jrwoods777@yahoo.com
}

Received 19 July 2014; published 26 June 2015; accepted 30 June 2015

Copyright (C) 2015 by author and Scientific Research Publishing Inc.

This work is licensed under the Creative Commons Attribution International License (CC BY). http://creativecommons.org/licenses/by/4.0/

\section{(c) (i) Open Access}

\begin{abstract}
While much work in biblical studies has been offered in the form of theological exposition and historical critical speculation of literary origins of the gospels, few modern biblical studies scrutinize the language of these gospels from rigorous linguistic criteria. This paper takes a discourse analytic approach from the field of Systemic Functional Linguistics (SFL) founded by M. A. K. Halliday. The notion of cohesive chaining is taken in order to evaluate the level of literary unity in the original Greek of the episode of the transfiguration narrative found within the Gospel of Matthew. Cohesive chaining will be defined; its function within the greater sociolinguistic theory of SFL will be examined, and then the concept will be directly applied. The study concludes with a unique contribution demonstrating how these cohesive chains are then unified via choices in verbal aspect as the grammar that not only solidifies semantic continuity among those chains, but contours the discourse using a scheme of markedness that signals the prioritization of its message. The hope of this study is to reinforce the recent paradigm shift of biblical research utilizing modern linguistic paradigms as tools to transform biblical interpretation and exegesis into a rigorously discourse-centered linguistic methodology.
\end{abstract}

\section{Keywords}

Cohesion, Discourse Analysis, Linguistics, Markedness, Verbal Aspect

\section{Introduction}

This essay will examine the cohesive ties running through the text of Matthew's Transfiguration account (17: pp. 1-13). This analysis views these linguistic resources as demonstrating that Matthew's account is a linguistically unified and situationally responsive use of an episode of Jesus' life. This study is offered in the hope that further linguistic studies will be conducted from it because Hallidayan framework has already been specifically fruitful in cohesive studies of text analysis outside of the Gospels (Van Neste, 2004; Reed, 1999: pp. 28-46; idem., 1997: 
pp. 188-218). First, a definition of cohesion will be established from a Hallidayan Systemic Functional Linguistic (SFL) perspective which itself has been proven useful in recent biblical scholarship (Martin-Asensio, 2000). Then examples of cohesion will be given. Finally, the framework of cohesion will be applied to the transfiguration episode in Matthew's Gospel. I will conclude with a sociolinguistic interpretation of Matthew's transfiguration episode as an instance of social discourse.

\section{Place of Cohesion in the Linguistic System}

Understanding cohesion requires understanding its placement in the general linguistic framework of SFL as a realization of one of the semantic systems of language (Halliday \& Hasan, 1976: pp. 26-27). This framework will be examined from two perspectives which have a stratified relation: firstly, cohesion's broader relationship out of the context of social situation and culture, and lastly, its direct contribution within linguistic expression of social discourse.

\subsection{Broader Stratified Relation to Social Context}

There are three general areas of "human experience" which discourse seeks to construe: the "field", or general activities conveyed within culture, the "tenor", or role relationships enacted between the members of a culture, and the "mode" or channel and organization of a message within culture (Halliday, 1985: p. 30; cf., Halliday, 1978: p. 129). These categories "field, tenor, and mode" reflect the "ecological matrix" which constitute what Halliday calls the greater "context of culture" and it is forms of discourse that use language to socially construe them (Halliday \& Matthiessen, 2006: p. 321; Martin, 2001: p. 45; Halliday, 1985: pp. 29-30; cf., also Lukin et al. 2011: p. 193). Halliday also observed a tendency of social convention from culture that seeks to develop a governing predictability over language by maintaining strong associations between language use and "situation types” within the structure of society (Halliday, 1978: p. 111, 157; Halliday, 2007: pp. 231-248; O' Donnell, 1999: pp. 251-252). This governance can be seen in Halliday's reference to "code” enforcement. Halliday refers to "code" as "governing the choice of meanings by a speaker and their interpretation by a hearer ... The code controls the semantic styles of the culture ... it determines the semantic orientation of speakers in particular social contexts.” (Halliday, 1978: p. 111; Halliday, 2007: pp. 231-248). Such cultural convention reinforces which lexicogrammatical selections from the macro-level of field, tenor, and mode will be "appropriate" to use within the micro-level "context of situation" as it feeds back into that larger cultural context (Halliday \& Hasan, 1976: pp. 21-28, 52). Reed offers an insightful paraphrase of this phenomenon.

"Halliday is suggesting that changes in the context of situation contribute to changes in the use of language. Speakers/authors conform their discourse to the context of situation, and consequently draw upon accepted forms of language that others recognize as appropriate for that situation.” (Reed, 1997: p. 54).

This situation-specific phenomenon represents a certain "register" of speaking (Halliday, 1978: pp. 110-111; Halliday, 2007: pp. 181-182; Halliday \& Hasan, 1976: pp. 21-26). Figure 1 illustrates the stratified relationship between the register of language as a "semantic configuration" (via metafunctions ideational, interpersonal, and textual) and the elements of the greater social context (Lukin, 2011: p. 192; Hasan, 2009: p. 170; Halliday \& Hasan, 1989: p. 55; Hasan, 1995: p. 231).

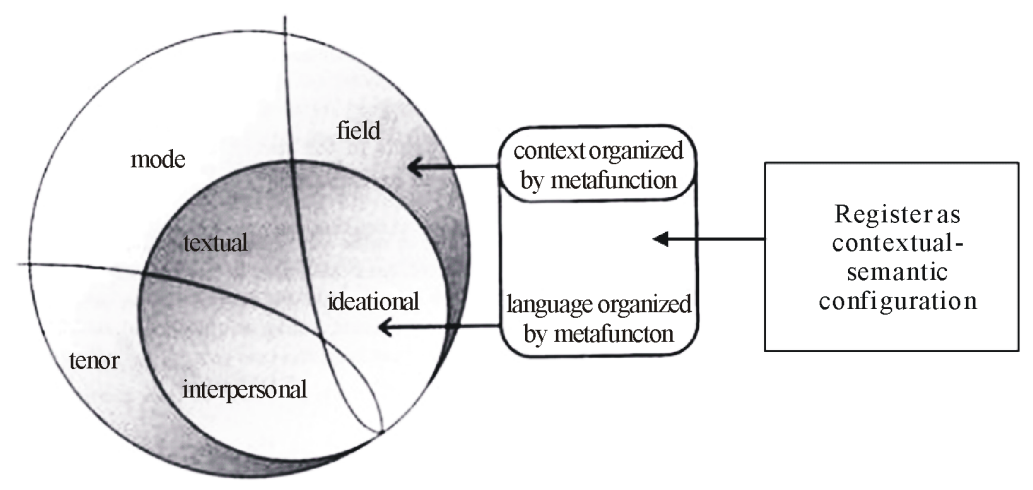

Figure 1. Register: language reflecting situation types within a cultural (Martin \& Rose, 2007: p. 297). 
While registers are not produced by any one member of society, a "register analysis" of any single text does help reveal the contribution it makes in this regard (Porter, 2004: pp. 220-233). A full-scale register analysis is not within the scope of this essay, but those elements found to contribute toward cohesive harmony of the text may be considered as the key semantic fields and lexical selections formative for the register that gave rise to the discourse. Cohesion, therefore, may be understood as a single dimension of register analysis (Porter, 2004: p. 224; Teich, 2009: p. 122).

Matthew's account then represents a single linguistic contribution toward a larger cultural phenomenon. It was this unique and central situation which forced the Jesus group to appropriate a normative linguistic expression for the identity and resurrection of Christ. Register concepts may also lead to criteria for "authenticating the words of Jesus" from the Gospels as well (Porter, 2004: pp. 210-238). No doubt, it was thrust upon the apostles as a peculiar and unprecedented "context of situation" that required their immediate management (Halliday, 2007: p. 180; idem, 1978: 28-29). This helps to illuminate their motivation to quickly establish so much literature and preaching (cf., Luke 1:1; Acts 5:42). Trying to attain some measure of predictability would only have been a natural impulse. They desired the predictability which carving out a linguistic register within the larger social structure could provide (Reed, 2000: pp. 121-153). Reed sees Paul trying to establish a dialect for much the same functional reasons, though I would agree with Halliday that early Christianity was constructing a "technical register" out of their unique situation type (i.e. life and resurrection of Jesus) to be able to embed within various societies, i.e. “antilanguage.” (Woods, 2013; Halliday, 1976).

Though a descriptive linguistic account of this contribution may be offered, one limit of this study is that it cannot reach hard conclusions about the entire set of registers of early Christianity in this regard. Indeed, the Gospel of Matthew portrays Jesus as engaging many arenas: rabbinic circles, prophetic activities, public appearances, family relations, etc. It may be implied then that the disciples were trained to interact among these various "situation types" in society through the activity of their leader prior to his death and resurrection. If the cohesive ties speak strongly toward a unified discourse of this section, then this may be seen as Matthew's "contextual configuration" which he offers to shape a larger register demanded by his context of situation (Hasan, 1995: 231; Halliday and Hasan, 1989: 48, 55, 88-96). It would be his way of using language to reinforce the issues most directly influencing the "solidarity" that could maintain the "social identity" of his fellowship in Christ within the greater Jewish and Greco-Roman context (Halliday and Hasan, 1976: 186; Hasan, 1995: 229; Rohrbaugh, 2007: 179-181; Hudson, 2001: 106; Schmidt, 2001: 22). This topic, however, lies beyond the scope of this essay. Language here represents one of the foundational mediums through and by which social identity and change may be transmitted and modified. As such, cohesive ties that unify such social discourse may be interpreted as representative of the predominant issues for which it was designed to "socialize" its audiences (Halliday, 1978: 99; Halliday and Hasan, 1989: 41).

Kress relates the ability of language in this regard as tending specifically to the perception of social distanciation and power: "Language provides the most finely articulated means for a nuanced registration of differences of power in social hierarchical structures, both as a static system and in process.” (Kress, 1989: 52). In light of this, Matthew may be viewed as issuing common themes about Jesus that seek to distance itself from competing views. Considering how quickly the Christian movement spread throughout the Mediterranean, and the kind of resistance it was met with, it is little surprise that different communities would quickly develop their own socialized expression of certain topics whether informed by apostolic precedent or not. Matthew's gospel material then may be seen as a means of codifying a linguistic constraint for such communities. See Keener who observes the situation for Matthew's audience is "struggling with those they believe to be illegitimate spokespersons" (Keener, 2009: 49). The cohesive ties that unify this text would function as that material which would be most essentially formative to this goal. See Meeks for an excellent study of "resocialization" in the early Christian community (Meeks, 1986: 13).

\subsection{Direct Semantic Contribution}

A unified text of social discourse will have simultaneously running through it three predominant semantic threads according to the Hallidayan framework: 1) ideational, 2) interpersonal, and 3) textual (Halliday, 1985: 29-30; Halliday, 1978: 128). While Halliday makes it clear that a sentence creates its own internal unity "by virtue of the structure" itself, a text larger than the sentence is "not a structural unit" but a semantic one. There are other metafunctional representations of Halliday's theory (Halliday and Hasan, 1989: 44). noting that the 
nomenclature "ideational” conflates “experiential” with "logical.” (Fawcett, 2000: 51, 72, nt. 20). Halliday asserts that a text as a cohesive "semantic unit" is "not composed of sentences but is realized in sentences" (Halliday, 1978: 135). Though the role of structure will be discussed later, it is clear that text or discourse requires linguistic devices and relations which do not rely on grammatical structure. Because cohesion works to achieve this very end, it is found among the semantic systems which realize the textual metafunction of language (Halliday and Hasan, 1976: 120). As a textual resource in the semantic system, the function of its lexical and grammatical connections serves to provide general organization for the discourse (Halliday, 1985: 532; cf., Stubbs, 1983: 15-19).

\section{Cohesive Relations}

There are five general types of cohesive relation identified by Halliday and Hasan: "reference, substitution, ellipsis, conjunction, and lexical cohesion” (Halliday and Hasan, 1976: 4; Halliday and Hasan, 1989: 73; Halliday, 1985: 532-538; Gregory, 1988: 311; Martin, 2001: 35. Cf., also Porter, 1999: 304-307). Cohesion setting “discourse relations which transcend grammatical structure" makes it possible to set these semantic relations between units of any size, direction (i.e., anaphoric, or cataphoric), or distance of separation (Halliday and Hasan, 1976: 14; Halliday and Hasan, 1989: 71; Stoddard, 1991: 15). It is, therefore, capable of connecting at almost any level of the "syntactic rank scale" of the linguistic system, i.e., word, word group, clause, etc. (Tucker, 1998: 41; cf., Halliday, 1985: 7-10) See chart in Halliday and Hasan, 1976: 29. The relations may also incorporate adjacent uses of tense as capable of cohesive tie (Gledhill, 2009: 65-84). Their relation is such that when one unit shows to be related to another, the former is reliant on the latter for meaning or otherwise could remain too enigmatic for interpretation (Halliday and Hasan, 1976: 4-5). Examples are provided below.

\subsection{Examples of Cohesive Tie}

The simplest example is when there is a relationship made between parallel units in the rank scale, as in the case of John and he below.

John is running for office. He is expecting to win by a landslide.

After having read both clauses, understanding who the pronoun he stands for in the second clause is revealed by a cohesive tie to John in the first. This type of relation may also be expanded to entire word groups as the next example illustrates.

The neighbors grow yellow Chrysanthemums.

a) I could grow RED ONES.

b) I could grow the SAME.

c) I could grow some (TOO).

d) I could grow some of the SAME (Halliday and Hasan, 1976: 110).

The concept of presupposition is foundational to cohesion. Statements a) through d) establish the lexical connections with the surrounding co-text to supply an interpretive constraint to meaning. It stands, therefore, that the absence of such connections renders a corresponding loss of constituent interpretability. Here much of the relations instantiate at the word or word group level, in this case relating "yellow Chrysanthemums" to the capitalized terms in various ways. Moving further along the rank scale, the following shows relations toward larger linguistic structures where the parenthetical remark is assumed to remain presupposed (Halliday and Hasan, 1976: 138).

a) You're tired.

b) Are you tired?

c) You're not tired?

d) Aren’t you tired? Yes. (I am tired.) (Halliday and Hasan, 1976: 138).

As one can see, the term "Yes" taken in the absence of presupposition renders interpretation impossible (Halliday and Hasan, 1989: 75). In this case, no one reading the text would be able to say what is being agreed to without the presupposed statement. Both what is presupposed from the linguistic context as well as the referring item itself share a two-way relationship (Halliday and Matthiessen, 2006: 84). The original clause elicits the production of the response, and the response relies on its presupposed clause for meaning (Halliday and Hasan, 1989: 55).

Hence, the surrounding co-text is both probabilistically influential as well as semantically reflective toward the utterance (Halliday and Hasan, 1989: 222). 
It is easy to see how the potential for complexity with cohesion could be considered as theoretically limit- less (Stoddard, 1991: 1). This is especially important when one considers such linguistic devices as word play, metaphor, poetry, "antilanguage", and so on (Halliday, 1976: 570-584). Indeed, being able to establish relations between any item of the linguistic system apart from structure allows for a tremendous range of possibilities to create the "texture" that constitutes part of the unity of a text (Halliday, 1985: 579-585; Halliday and Hasan, 1976: 2-3; Halliday and Hasan, 1989: 70-96; Stoddard, 1991). There are even times when entire units of discourse may be the referent. Consider the potential to draw connections to an entire discourse unit.

Gary: That's when it hit me.

My leg started jumping up and down. I just couldn't control my nerves.

J. R.: (That's) Terrible (Schiffrin, 1994: 220).

The comment which J. R. makes does not point back to any specific item in the discourse, but "presupposes everything that precedes" in order to interpret or predicate over the entire section of text (Halliday and Hasan, 1976: 14).

\subsection{Linguistic Structure Mapping Cohesion}

While the relations between cohesive ties is examined in this study as predominantly a non-structural one, structure can, however, act like a treasure map pointing to the relations it contains. Coming back to the example above, notice the "parallelisms" which aid in signaling and interpreting the paradigmatic alterations within the structure, as illustrated in Figure 2 (Halliday and Hasan, 1989: 81-82). See Fawcett (2000: 56, nt. 6) for an insightful discussion as to how the issue of structure was omitted from Halliday and Hasan's work, Cohesion in English (1976), not due to overlooking it, but because Halliday's work was designed specifically to focus on non-structural cohesion. Fawcett readily admits the importance of structure toward cohesion: "the fact is that TRANSITIVITY, MOOD, THEME etc. can also contribute to the 'cohesion' of a text, as Martin (1992) clearly demonstrates.” (Fawcett, 2000: 56). This was not a criticism of Halliday and Hasan's work, only to state that they understood this principle and that it was simply outside the stated scope of the work they created. Fawcett's criticism does, however, extend to those works which followed their work blindly producing the "unfortunate effect" of "incomplete" works on the topic later on. I have incorporated in this essay a limited attempt toward a more complete study of cohesion in the Greek NT (Fawcett, 2000: 56).

The structures themselves do not constitute the textual cohesion but seen from the oppositions in both the syntagmatic and paradigmatic axes, a repetition in structure renders cohesive relationships easier to recognize and interpret. This is because the syntagmatic axis for a text is neither haphazard nor completely autonomous but may well be driven by the impetus to recontextualize former elements in light of new developments in the discourse. Tucker's comment is especially astute here: "The 'autonomy of syntax' is not a principle of systemic functional linguistics. A major assumption in SFG is that the structural potential is the way it is in order to reflect the meaning potential” (Tucker, 1998: 61). See Fawcett (2000: 70-73, 152-154) for an excellent discussion of why Halliday may have been hasty in his early abandonment of this S-P-C-A nomenclature representing an "integrated syntax" (Halliday uses “combined”) of structure which the Cardiff Grammar has taken up.

\subsection{Cohesive Chains}

Identifying several of these cohesive ties in a sequence which runs through a text is called a "cohesive chain".

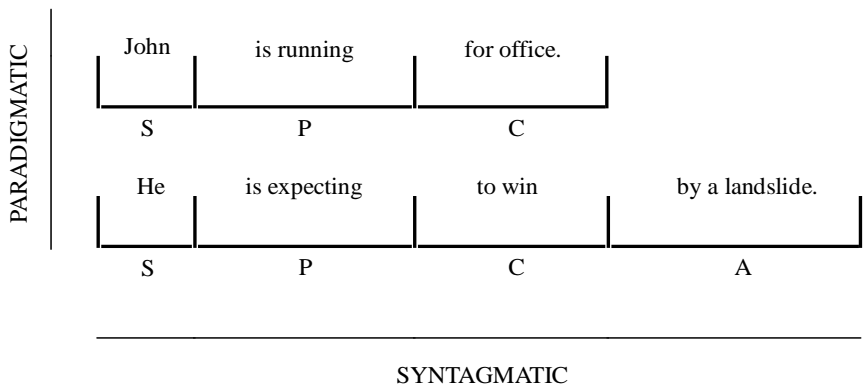

Figure 2. Parallel structure aids recognition of cohesive relations. (Fawcett, 2000: 70-73, 152-154). 
Halliday and Hasan have categorized such chains into two "typical” groups (Halliday and Hasan, 1989: 84). Refer to Figure 3 below for delineation according to their work.

These general categories will be operative in this essay. Discovering several sequences of cohesive tie within a text demonstrates a certain level of discourse unity. According to Halliday and Hasan, the major contribution which cohesion makes in affirming a stronger degree of "cohesive harmony" lies along the cline of the extent to which these cohesive chains interact with and support one another (Halliday and Hasan, 1989: 84). The semantic domains of each chain cannot remain in isolation, but must find "interaction" throughout the grammar of the discourse to finalize their contribution to unifying the text (Halliday and Hasan, 1989: 91; Martin, 2001: 40). Martin offers a helpful analysis of this phenomenon in his examination of a "feminist narrative" resource, Piggybook (Brown, 1989, quoted in Martin, 2001: 39).

\subsection{Chain Interactions}

\section{Piggybook.}

Mr Piggott lived with his two sons, Simon and Patrick, in a nice house with a nice garden, and a nice car in the nice garage. Inside the house was his wife.

"Hurry up with the breakfast, dear," he called every morning, before he went off to his very important job. "Hurry up with the breakfast, Mum," Simon and Patrick called every morning, before they went off to their very important school.

After they left the house, Mrs Piggott washed all the breakfast things... made all the beds... vacuumed all the carpets... and then she went to work.

"Hurry up with the meal, Mum," the boys called every evening, when they came home from their very important school.

"Hurry up with the meal, old girl,” Mr Piggott called every evening, when he came home from his very important job.

As soon as they had eaten, Mrs Piggott washed the dishes ... washed the clothes ... did the ironing... and then she cooked some more.

Here, one can see a number of identity chains for each participant. See the example chains below.

- Mr Piggott-his-his-he-he-his-they,

- his two sons-Simon/Patrick-Simon/Patrick-they-their-they-the boys-they-their-they,

- his wife-dear-Mum-Mrs Piggot-she-Mum-old girl-Mrs Piggott-she.

Also notice the similarity chains utilizing various lexical semantic relations. Examples are below.

- Mr-sons-wife-dear-Mum-Mrs-Mum-boys-girl-Mr-Mrs,

- nice-nice-nice-nice/imporant-important-important-important/breakfast-breakfast-breakfast,

- house-garden-garage-beds-carpets (Martin, 2001: 40).

Analyzing the chains from a syntagmatic perspective, one can see that the repetition of the epithet nice occurs inside a repeated syntactical pattern of "epithet-thing" for various items in the meronymy chain for house, e.g., nice house, nice garden, nice garage. Mrs. Piggott's chain offers a contrastive syntax by key omissions. I will refer back to the rhetoric involved in omissions later on in Matthew's transfiguration account. See section 4.2.

\footnotetext{
Identity chains

These are instances of cohesive tie that all refer to the same person, place, or thing typically instantiated through either grammatical cohesion which utilizes pronominals, demonstratives, definite article, or comparatives, or through lexical cohesion which utilizes equivalence, naming or semblance. Similarity chains.

These are instances of cohesive tie related by either "co-classification" or "co- extension." These are "members of non-identical but related classes of things, or events." These are typically realized by substitution and ellipsis, as well as a full spectrum of general lexical relations such as repetition, synonymy, antonymy, meronymy, equivalence, naming and semblance.
}

Figure 3. Types of cohesive chain. (Halliday and Hasan, 1989). 
For instance, her introduction contrasts the previous items by an absence of the epithet nice, and her going to work contrasts the destinations of the males by its absence of the epithet important.

Elements within chain interactions may also strategically collocate with markers of discourse development which set the audience's expectations and characterizations of events within the plot (Puigdollers, 2009: 34). For example, Mrs. Piggott's chain shows an implicit compliance to the males' demands for food in the morning, and then her in- volvement becomes explicit when she has to clean their messes in the evening (Martin, 2001: 42). Here, the start of the day is marked by the explicit demands of the males, whereas the end of the day is marked by the explicit cleaning activities of the wife.

The contrastive parallelism is manifested through the absence and presence of cohesive ties in a reasonably predictable manner. During the morning scene, the plurality of demands by the males sets their collocation alongside the wife's implicit obedience to respond (Halliday and Hasan, 1989: 81). This structure expectedly shifts in the nighttime scene where the explicit mention of the plurality of the wife's activities is collocated with the absent response of the males. One can see that multiple dimensions of discourse function such as topic management, plot development and chronology may find their place in the textual structure of the ties that signal their emerging boundaries (Morley, 2009: 5; cf., Halliday and Hasan, 1989: 94). It is not the mere existence of cohesive chains that unifies the texture of a discourse, but the interactions they instantiate between these chains through the grammar (Halliday and Hasan, 1989: 91).

\section{Examination of Matt 17:1-13}

This study will now move to a direct examination of the cohesive chains in the text of Matthew's transfiguration account according to the NA28. The chains are as follows: 4.1 Identity Chain for Jesus; 4.2 The Supernatural;

4.3 The Disciples; 4.4 Conjunctive Chain; and 4.5 Imperfective Aspectual Chain. See Table 1 below for the identity chain for Jesus.

\subsection{Identity Chain for Jesus}

The first notable aspect of the identity chain for Jesus (see Table 1) is its "text exhaustive" status through the narrative (Halliday and Hasan, 1989: 84). In other words, Jesus is referred to at every point throughout the development of the narrative plot. The single exception to its exhaustive nature might be considered at the clause in v. 6 where it says that the disciples became terrified and fell on their faces. However, when one considers that it is their reception of the statement about the Son from the voice in the cloud which is the cause of this fear, Jesus carries a bit of secondary influence even within that verse as well. It the very exhaustive nature of this chain which may supply the impetus behind commentators who feel the need to offer a full topical study for every referent embedded in the narrative's "variety of allusions" because it would be tempting to see every referent as predicating Jesus (Keener, 2009: 437). Davies and Allison (2004) are the quintessential example of how their 92 explicit references to "Moses" between pp. 685-741 actually distract the audience from the linguistic issues

Table 1. Chain indentifying Jesus through Matt 17:1-13.

\begin{tabular}{|c|c|c|c|}
\hline v. $1 \pi \alpha \rho \alpha \lambda \alpha \mu \beta \alpha ́ v \varepsilon \varepsilon$ & $* \dot{\eta} \mu \tilde{\alpha} \varsigma$ & 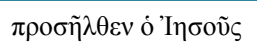 & $\lambda \varepsilon ́ \gamma \omega v$ \\
\hline 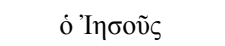 & घĩv $\alpha 1$ & $\dot{\alpha} \psi \alpha ́ \alpha \varepsilon v \circ \varsigma$ & 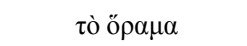 \\
\hline$\dot{\alpha} v \alpha \varphi \varepsilon ́ \rho \varepsilon \imath$ & $\Theta \varepsilon ́ \lambda \varepsilon 1 \zeta$ & $\varepsilon \tilde{i} \pi \varepsilon v$ & ó viò $\varsigma \tau o \tilde{u} \alpha \dot{\alpha} \theta \rho \omega ́ \pi$ ov \\
\hline v. $2 \mu \varepsilon \tau \varepsilon \mu о \rho \varphi \omega ́ \theta \eta$ & бoì & 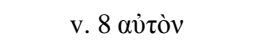 & v. $10 \alpha$ น่นòv \\
\hline$\alpha \cup ̉ \tau o \tilde{~}$ & v. $5^{*} \alpha u ̉ \tau o u ́ \varsigma$ & 'Iฤбoṽv & v. 11 ó \\
\hline 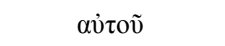 & oṽนós & 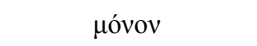 & 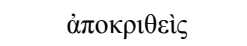 \\
\hline v. $3 * \alpha u ̉ \tau o \tilde{\varsigma}$ & $\dot{\varepsilon} \sigma \tau \iota v$ & 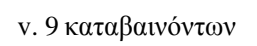 & $\varepsilon \tilde{i} \pi \varepsilon v$ \\
\hline$\alpha \cup ̉ \tau o \tilde{~}$ & ó vió $\varsigma \mu$ ov ó $\alpha \gamma \alpha \pi \eta \tau o ́ \varsigma$ & $\alpha u ̉ \tau \tilde{\omega} \nu$ & v. $12 \lambda \dot{\varepsilon} \gamma \omega$ \\
\hline 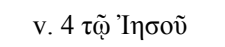 & 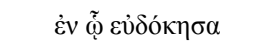 & $\dot{\varepsilon} v \varepsilon \tau \varepsilon i ́ \lambda \alpha \tau o$ & 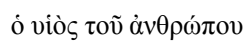 \\
\hline 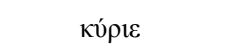 & $\alpha$ น่นป̃ & ó 'Iๆ & $\mu \varepsilon \dot{\lambda} \lambda \varepsilon \iota$ \\
\hline
\end{tabular}

* = ambiguous reference Pronouns by their nature often carry ambiguity though a discourse. Here it is uncertain whether Jesus is included in this collective pronoun or not, as the disciples may be seen as being differentiated from Jesus (Halliday and Hasan, 1989: 89). 
running through the text in place of a wealth of knowledge on a topic that is given no elaboration in this section.

Functional analysis of cohesive chains extends further than simply textual unity. As formerly demonstrated, authors will often signal the development of a discourse by thematic collocations which are strategically paired with each of the nodes within their cohesive chains (Halliday and Hasan, 1989: 50, 81-82; Tucker, 1998: 94-96). The concept is a synthesis of structural "parallelisms" in the text which motivate the lexical collocations. Halliday and Hasan speak of the "interdependence between grammatical and lexical cohesion." (Halliday and Hasan, 1989, p. 82). Tucker observes that "each lexical item possesses its individual grammar, its unique set of collocates.” (Tucker, 1998: 96). This concept is especially seen in the relationships which the syntagmatic and paradigmatic axes have with cohesion, as aforementioned. So that, as the lexemes of each chain are used, they motivate the collocation of systemically and/or semantically related sets of terms and the grammatical structures that can realize their relations. This is manifested in the chain interactions that unify both the chains themselves as well as the overall text to communicate key issues in social discourse.

See the discussion below on how the identity chain for Jesus collocates with that of the disciples oscillating both case and function to open and close the activity section of the transfiguration. It can be seen as no coincidence that the repetition of an explicit grammaticalization of Jesus' name, $\dot{o}$ 'I $\eta \sigma o v \tilde{\zeta}$, appears at key moments through the narrative structure.

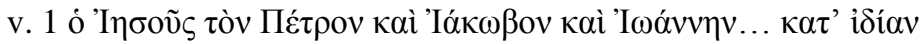

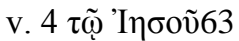

v. 7 ó 'Iฤбoũ

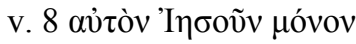

Verses 1 and 8 help audiences to process the textual structure which surrounds the section's primary epicenter

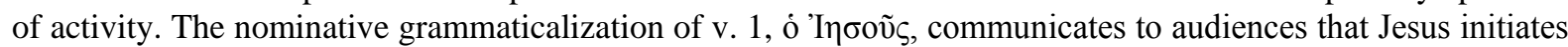
the scene prior to the start of the divine activity. Additionally, the collective use of the article covers the disciples who are appropriately in the accusative as receptors of Jesus' activity (Porter, 1999: 88, 110). The accusative functions as "direct object" of the verb and Porter uses Matt 17:1 as an example not covered under the Granville Sharp rule where the article "covers several personal names.” This sets an important pattern for the structure of the episode because a similar pattern is paralleled at the conclusion of the activity where another

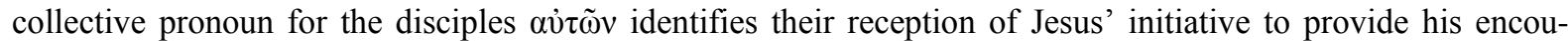

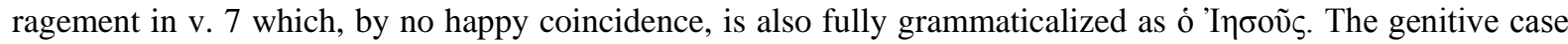
of the collective pronoun for the disciples in v. 7 is accounted for by the functional use of it as the direct object

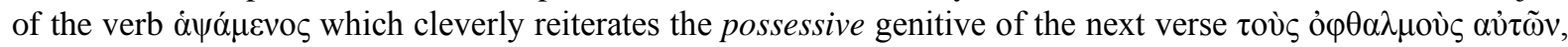
thereby setting the cohesive ties through the grammatical structuring (Porter, 1999: 94, 130). The close of the

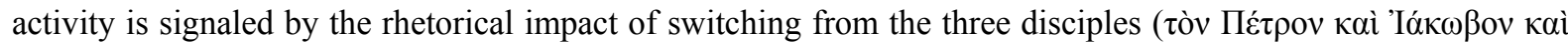

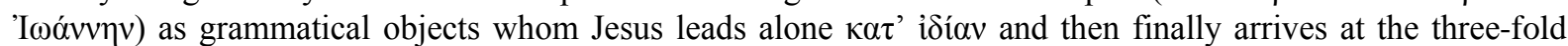

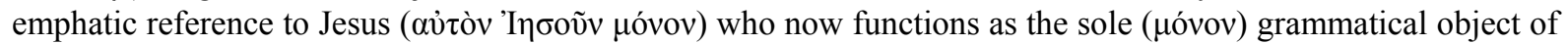

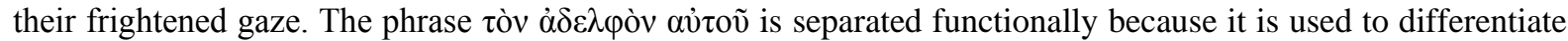

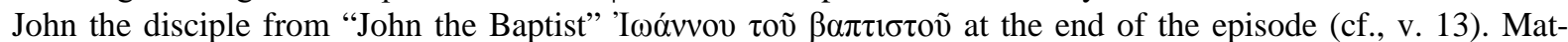
thew's choice of the article $\tau$ òv for the collective grammatical object in v. 1 both foreshadows and culminates toward the intensive av่òv for Jesus at the activity's completion.

Therefore, rather than viewing the use of the article here as "highlighting" any one disciple in particular, the discourse function of the article demonstrates the cohesive nature of the boundary markers framing the scene (Nolland, 2005: 698; contra Davies and Allison, 2004: 2, 694). This analysis is corroborated by Matthew's reflective use of the summative term tò ö $\rho \mu \alpha$ recognized by several commentators (Hagner, 1998: 498; France, 2007: 652; Newman and Stine, 1992: 541). Firstly, it occurs in the text at a point where it can cohesively tie with the whole of the activity anaphorically. Additionally, it establishes a similar type of "point of departure" relationship which the temporal phrase in $\mathrm{v}$. 1 served to introduce the entire scene coming out of the previous section (Levinsohn, 1995: 61; cf., Black, 2002: 211). The phrase in v. $1 \mathrm{~K} \alpha i ̀ \mu \varepsilon \theta^{\prime} \dot{\eta} \mu \varepsilon \dot{\varepsilon} \rho{ }_{\varsigma} \tilde{\varepsilon} \xi$ is a recognized "point of departure" introducing the transfiguration section which v. 9 has much in common with and is noted by commentators in various ways (Nolland, 2005: 699; Hagner, 1998: 484). Nolland recognizes v. 9 as a "change of scene" and Hagner notes that v. 8 is the "final verse" for the activity of this section. Keener's analysis (Keener, 2009: 436) sections all of 16:28-17:13 and offers no linguistic justification for doing so but lines up the thematic allusions within the text instead. Davies and Allison (2004: 684, 704-705) tentatively assume this to be the end of a chiasm at v. 8 though offering no linguistic justification. 


\subsection{The Supernatural}

This is a part of a more general similarity chain connecting each of the lexical references to the supernatural elements of the section, see Table 2 below (Louw and Nida, 1996: 33. 4488).

Since a great deal of commentary has typically focused on these elements, a few brief comments about some of the more popular lexemes identified in this chain are in order: particularly regarding Matthew's use of "high mountains" (v. 1 öpos vi $\psi \eta \lambda$ òv), and the appearance of "Moses and Elijah" (v. 3). Matthew’s use of "high mountains" for special activities of God is well known, though not every reference to a mountain should be regarded as programmatic for such activity; it is frequent and in this case applicable. (Hagner, 1998: 492; Nolland, 2005:

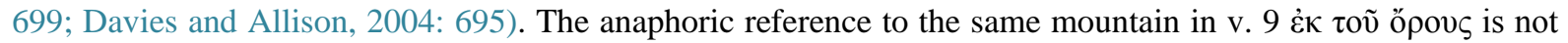
included in this chain because the supernatural action has subsided and so their direction is moving away from the epicenter of that activity. The separation may be regarded as thematic as well as geo-spatial, since demonic activity is taken up directly subsequent to the exposition of Elijah's coming (17:14-8).

Regarding the use of the passive in v. 3 to convey the "appearance" (v. $3 \ddot{\omega} \varphi \theta \eta$ ) of Moses and Elijah, see "failure of concord". (Porter, 1999: 75) Newman and Stine offer, "There appeared," as an acceptable translation. (So RSV, NRSV, NKJV) Though regarding Moses and Elijah as the actors of this verb (so ESV, LEB, ISV, NET), they quote the TEV which conveys a very different idea: "the disciples saw Moses and Elijah." Besides the cohesive tie with the frequent phrase of Matthew "Law and the Prophets" which Jesus fulfills (cf. 5:17; 7:12), the supernatural nature of their status also fits the context here (especially mentioned together in this manner) and this is confirmed by many commentators (France, 2007: 648; Hagner, 1998: 493; Davies and Allison, 2004: 698). While much commentary is devoted to their supposed symbolism, the following linguistic approach will shed a more well-defined light as to the possible rheotoric behind Matthew referring to their appearance in this discourse.

The primary concentration of activity in this chain lies within vv. $2-3$, and v. 5 which surrounds the interruption to the scene by the comments of Peter in v. 4. Then it breaks from the narrative until vv. 9 - 13 which is designed to focus solely on an exposition on the arrival of Elijah who is revealed to be John the Baptist in v. 13. This leaves open the question that the disciples have not asked in connection with the participants in the event. While they have seen and understood the arrival of Elijah in both the transfiguration vision as well as the contemporary role of John the Baptist, the corresponding vision of Moses has remained explicitly untethered to any equivalent role contemporary to their time and questioning. One can see the artistry implicit in the rhetorical affect behind the text's cohesive lopsidedness. Thus, even the absence of any explication for the role and appearance of "the vision" having to do with Moses coheres with Jesus' command for silence. The absence of other closer referents often reveals more general semantic relations. As asserted here: "the interpretation of items in the absence of a linguistic referent and/or any situational clues as well as the perception of semantic relation between un-interpreted implicit devices is made possible because of the third type of tie: that which is based on co-extension.” Jesus, then, by purposeful omission, could well be added to this list as a co-extensional tie with Moses (Halliday \& Hasan, 1989: 79). In terms of accounting for the linguistic references of this episode, Jesus,

Table 2. Chain for supernatural elements Matt 17:1-13.

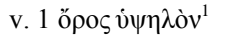

$$
\begin{aligned}
& \dot{\varepsilon} \pi \varepsilon \sigma \kappa i ́ \alpha \sigma \varepsilon v \\
& \text { v. } 2 \mu \varepsilon \tau \varepsilon \mu о \rho \varphi \omega ́ \theta \eta \\
& \varepsilon \bar{\varepsilon} \lambda \mu \mu \psi \varepsilon v
\end{aligned}
$$

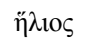

$$
\begin{aligned}
& \lambda \varepsilon v \kappa \grave{\alpha} \\
& \varphi \tilde{\omega} \varsigma \\
& \text { v. } 3 \ddot{\omega} \varphi \theta \eta^{2}
\end{aligned}
$$

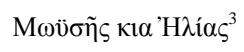

$$
\begin{aligned}
& \text { v. } 4 \text { кúpเe }
\end{aligned}
$$

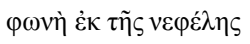

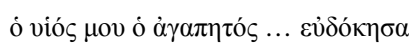

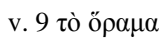

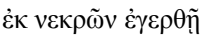

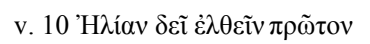

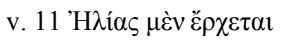

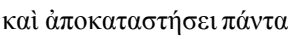

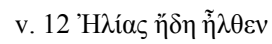

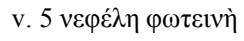


is then co-extensionally related to Moses by the role that he plays, while John the Baptist is explicitly so with Elijah. Of course, nearly every commentator draws the thematic connection this way, but not from specifically linguistic criteria.

One might object to the missing reference in this chain to the title "Son of man" which Jesus uses for himself. The reasons for leaving it out of this chain have to do with the larger chains of discourse within which the two titles "Son of Man" and "beloved Son" of God are embedded in Matthew's Gospel. The two titles used of Jesus create a "paradox" with which the disciples must grapple throughout the narrative. (France, 2007: 652) The "beloved Son" title already has glory directly associated with God through different scenes (1:18-25; 2:15; 3:17). (Luz, 2001: 398) These were "theophanic" episodes that were not difficult to understand. (France, 2007: 121; cf., Duling, 2012: 84) The title, "Son of Man," however, this study would argue carries an as yet unfulfilled glory that relies on the death and resurrection. (Nolland, 2005: 695) Regarding their cohe- sive contributions, the title "Son of Man" corresponds well with Jesus' statements about his needing to die, which by no coincidence directly collocates with both this section and those surrounding. (cf., vv. 16:21; 17:9, 12, 22-23) Hence, it is Jesus, and not God, who is the one to declare his death. Moreover, it is Jesus' announce- ment of the "Son of Man's coming in his kingdom" which would have challenged the disciples with a mystery in need of resolving (16:28). This identifies the very cognitive dissonance they associated between the concepts: how the death of their leader could be construed as bringing about the kingdom of God. This supplies the impe- tus for ordering of the transfiguration first with two dead historical figures, Moses and Elijah, and corresponding exposition which harbors the resuming implicit references to the arrival of the kingdom. The disciples' persis- tent misunderstanding of the significance of Jesus' death prevents further elaboration, until they put all the pieces together at the resurrection event itself. (Davies \& Allison, 2004: 713) Contrastively, the title which God confirms about his "beloved Son" coheres well with the chains of supernatural activity which the disciples show less struggle understanding but about which are commanded to remain silent until they perceive its purpose clearly. (France, 2007: 648)

\subsection{The Disciples}

This identity chain for the disciples (see Table 3) encompasses both the references to "Peter" and "the disciples" for two reasons. Firstly, Peter is represented as a leading figure for the disciples as a whole. (Blomberg, 1992: 270; cf., Davies \&Allison, 2004: 695, nt. 56. France, 2007: 645) Secondly, the three participants of the event are referred within a "collective" reference throughout much of this episode. (Porter, 1999: 131, 134) Peter and the disciples also have a text exhaustive status in the action. One can perceive the contrast between the types of role portrayed by this chain and that of Jesus. The examples are numerous. Their passivity into the events con- trasts Jesus' leadership. They do not receive the glistening changes that Jesus does when the cloud arrives. They are not identified by the voice as is Jesus and they receive commands from both Jesus and the voice from the cloud. In fact, besides the narrator's mention of Peter's ignored comment in v. 4, this is the last time Peter, James, and

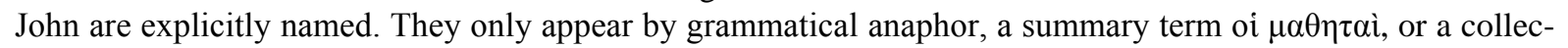
tive pronoun. The lexemes used to record the disciples' reaction to the event do juxtapose Jesus' nonchalant reciprocation with the ancestors on a semantic level, but in terms of narrative continuity is closely connected as signaled by Matthew's grammatical usage, as will be demonstrated below. The semantic contrast is seen

Table 3. Chain identifying the disciples through Matt 17:1-13.

\begin{tabular}{|c|c|c|c|}
\hline 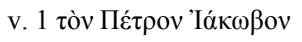 & $\varepsilon \tilde{i} \pi \varepsilon v \dot{\eta} \mu \tilde{\alpha} \varsigma$ & ह̌兀 $\varepsilon \sigma \alpha \nu \alpha \nu ่ \tau \tilde{\omega} \nu$ & $\alpha$ \\
\hline 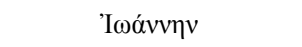 & & $\dot{\varepsilon} \varphi \circ \beta \eta \dot{\eta} \theta \eta \sigma \alpha \nu$ & $\varepsilon i \pi \eta \tau \varepsilon$ \\
\hline$\tau o ̀ v ~ \alpha ̉ \delta \varepsilon \lambda \varphi o ̀ v ~ \alpha u ̉ \tau o \tilde{v}$ & 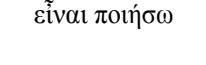 & v. $7 \alpha \cup ̉ \tau \tilde{\nu} \nu$ & 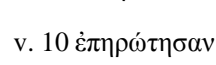 \\
\hline$\alpha$ & v. $5 \alpha$ นоข๊ & $\dot{\varepsilon} \gamma \varepsilon \dot{\varepsilon} \rho \eta \eta \tau \varepsilon$ & oi $\mu \alpha \theta \eta \tau \alpha i ̀ ~$ \\
\hline$\kappa \alpha \tau^{\prime} i \delta i ́ \alpha \nu$ & $\lambda \alpha \lambda \mathrm{o} \tilde{v} \tau \mathrm{\alpha}$ & $\mu \grave{\eta} \varphi \circ \beta \varepsilon \tilde{\imath} \sigma \theta \varepsilon$ & $\Lambda \varepsilon ́ \gamma о \nu \tau \varepsilon \varsigma$ \\
\hline v. $2 \ddot{\varepsilon} \mu \pi \rho \circ \sigma \theta \varepsilon v \alpha v ่ \tilde{\omega} v$ & 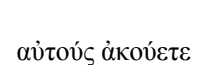 & v. $8 \varepsilon \dot{\pi} \alpha \dot{\rho} \alpha \nu \tau \varepsilon \varsigma \alpha u ̛ \tau \tilde{\nu} \nu$ & v. 12 ช่ $\mu \tilde{\tau} v$ \\
\hline v. $3 \alpha$ นò & & & 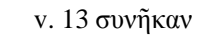 \\
\hline 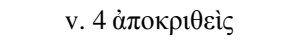 & 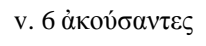 & عĩ்ov & oi $\mu \alpha \theta \eta \tau \alpha i ̀ ~$ \\
\hline 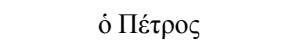 & oi $\mu \alpha \theta \eta \tau \alpha i ̀$ & v. $9 \kappa \alpha \tau \alpha \beta \alpha \iota{ }^{\prime} v \tau \omega \nu$ & $\alpha u ̛ \tau o i ̃ \varsigma$ \\
\hline
\end{tabular}




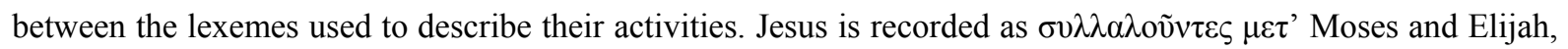
and this carries "a clear implication as to reciprocal response." (Louw \&Nida 1996: 33.157) In confirmation, Luke mirrors this mutual reciprocity in his version of the transfiguration which he portrays as everyday conversation (cf., Luke 4:36; 20:5; Acts 10:27). Semantically this is a clear contrast to the disciples' reaction which is both repeated $\varphi о \beta \varepsilon ́ o \mu \alpha$ (vv. 6-7) and intensified $\sigma \varphi \delta_{\delta} \rho \alpha$ (v. 6) and is usually associated with the fear of death. (cf., Matt 10:28; Acts 5:26). Grammatically, however, it makes narrative sense to provide continuity between them in an effort to directly associate the contrast (see next section on conjunctive chain). The only comment Peter makes receives no acknowledgment and this is contrasted by the discourse of Jesus whose words the disciples learn to cling to as an explanation which helps them understand a lesson they presumably needed to know. Clearly, they are there to receive and witness the vision to change their perceived relationship and reaction toward Jesus.

\subsection{Conjunctive Chain}

Conjunctions (see Table 4) do more than simply connect individual words. As Porter and Brook O’Donnell have demonstrated, they help to construct all levels of discourse: word, clause, clause complex, and para- graphs. (Porter \& Brook O’Donnell, 2007: 9) The analysis they offer for the "three axes" of conjunctive function is offered below in paraphrase.

Three Axes of Conjunctive Function Operate in Discourse.

1) The "vertical" dimension represents clines of discourse (e.g. sentence, paragraph, etc.)

2) Two "horizontal" dimensions represent:

a) continuity/discontinuity

b) logical-semantic relations (Porter \&Brook O’Donnell, 2007: 8)

This analysis will be adopted here. The "vertical" pericope boundaries of this section represent the first order of consideration.

In this regard, the conjunctive chain through this section of Matthew begins and ends the action sequence of the narrative, i.e. vv. 1 - 8, incorporating the "highest level of discourse continuity" (i.e., $\kappa \alpha$ ) placed between the expositional frames on either side, cf., Matt 16:24-28; 17:9-12. (Porter \& Brook O’Donnell, 2007: 10; cf., Black, 2002: 112) This is for good interpretive reason. The section prior to the start of the action has Jesus elaborate

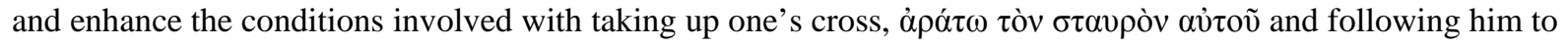
whatever end with the exhortation that their soul is what needs preserving. Having grammaticalized the continuity, it is little surprise that when the scene of the transfiguration arrives, this principle of the soul's survival is witnessed in living action. (Porter \& Brook O’Donnell, 2007: 10)

The souls of the great prophets Moses and Elijah are seen not only as living despite having died many years prior but also are seen as engaging fellowship with Jesus. Here lies the motivation behind Matthew's placement of the word group kaì íovi in v. 3 because it is an event that calls the readers to take special notice. Kai íov́ represents an interpersonal theme which "does not add to or restrict the content of what is happening in the sentence.” Therefore, Black asserts that its sole reason for inclusion in Matthew's narrative framework is to communicate, "Hey, look! Something important or unexpected is happening here!" (Black, 2002:134-135) This is also why Peter's comment is sectioned off with the use of $\delta \dot{\varepsilon}$ because Matthew communicates that although it is

Table 4. Conjunctions through Matt 17:1-13*.

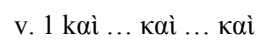

$$
\begin{aligned}
& \text { v. } 8 \delta \grave{\varepsilon}
\end{aligned}
$$

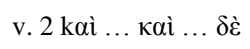

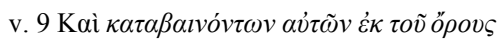

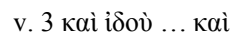

$$
\begin{aligned}
& \text { v. } 10 \text { kà̀ ... oũv... ö } \\
& \text { v. } 4 \delta \dot{\varepsilon} \ldots \varepsilon \dot{\imath} \ldots \kappa \alpha \grave{~} \ldots \kappa \alpha \grave{~}
\end{aligned}
$$

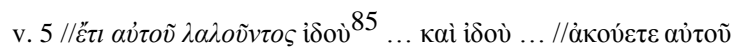

$$
\begin{aligned}
& \text { v. } 11 \delta \grave{\varepsilon} \ldots \mu \grave{\varepsilon} v
\end{aligned}
$$

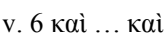

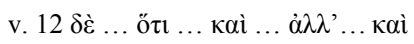

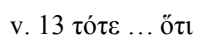

*// = asyndeton italicized = Genitive absolute. A genitive absolute construction in the absence of another conjunction is considered asyndetic. (Black, 2002: 134) 
chronologically alongside the action, it is characteristically out of sync with it. (Louw and Nida, 1996: 89.87; Black, 2002:154) While Louw and Nida have correctly seen this as in one sense a "marker of a sequence of closely related events" what is notable is the unusual Predicator-Subject (P-S) construction, especially when the construction includes a grammaticalized subject when S-P structure is the usual collocation with the $\delta \dot{\varepsilon}$ conjunction. (Black, 2002:155) This is because it is not the presence of Peter that represents the discontinuity, since he was already accessed on either side adjacent to this episode. What directly represents the point of discontinuity

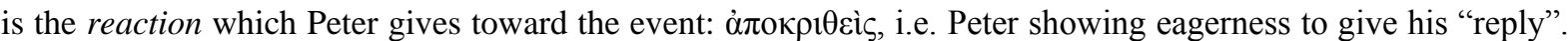
(Louw \& Nida, 1996: 33.184) So then Matthew's communication is two-fold: 1) that Peter's reaction is chronologically sequenced alongside the event, and 2) that it is also disruptive to it. The corresponding genitive absolute conveys well the need to squelch Peter's attempt to show off his veneration. Peter's response is characterized as "self-assured forwardness." Hence, Matthew's motivation for portraying it as a development in response to, but at discontinuity with the narrative. This then could be the motivation behind the textual variant here at $\mathrm{v}$. 4 which some have in the plural $\pi$ oin $\sigma \omega \mu \varepsilon v$ to soften Peter's remark. The single reading, however, has earned the "almost certain” judgment by the committee. (Metzger, 1994: 34). Rather than contrasting the principle that Matthew previously mentioned, i.e., "repay a man for what he has done" (16:27), it all the more embodies it with an ironic twist. While Jesus is rewarded with God's endorsement, Peter is rewarded, as it were, with the command to listen to Jesus. This is because Jesus has already warned Peter against having his mind set on earthly things (16:23) and here Matthew shows us that the rebuke from Jesus has not produced the impact that was intended. Hence, God himself arrives in the cloud in order to override P ter's attempt to establish an earthly mark of glory to drive into him a silent receptive state.

At this stage of the episode Matthew provides his readers a quotation by God which both identifies Jesus

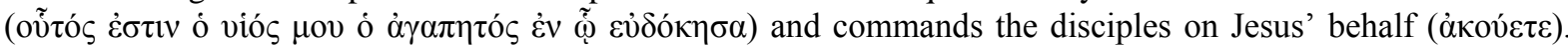
The fear they experience proves successful in producing its intended results, i.e. silence. Jesus' encouragement is painted as having an "unmarked continuity" in direct response to their fear. Unfortunately, many translations have transposed the semantic relations between the disciples' fear and Jesus reaction into the grammar by choosing to place a contrastive English connective but, cf., ESV, ISV, NIV, NKJV, RSV, NRSV, TNIV. The contrast lies in the semantics of the lexemes rather than the grammar which Matthew chooses to cohere them (Porter \& Brook O’Donnell 2007: 11; cf., also Black, 2002: 137-140) The practice of distinguishing between conjunctive meaning and semantic context must be maintained. Other translations keep the continuity, such as the ASV, LEB, NASB95 which all translate "And." The NLT, however, cleverly uses the conjunction "then" which may more properly signal the sort of immediate reactionary connection intended. The best translation strategy may lie with finding the intersection between narrative continuity and immediate personal agency using either "and then," or "and so" since "and" communicates the continuity, while either "then" or "so" communicates the latter by either chronological or causal means.

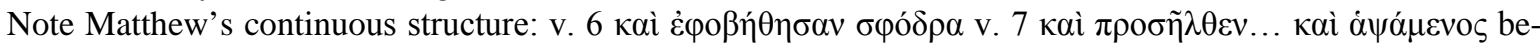
sides being assigned a different verse number, the Greek text shows no grammatical break between these events.

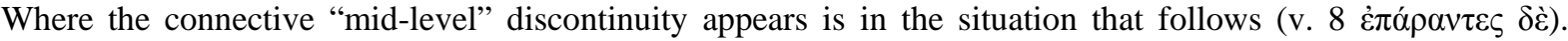
(Black, 2002: 153) This grammatical strategy communicates another development that the disciples' (now corporately referenced) reception of Jesus' exhortation "not to fear" is no longer met with either insolent resistance as the episode prior, or concern for earthly glory like Peter's most recent response, but now at long last it is met

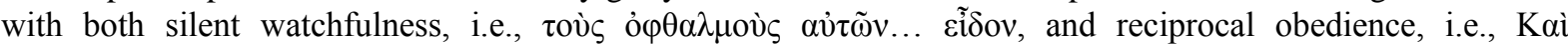

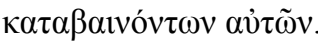

Having learned their lesson, Matthew proceeds with Jesus' projected frames to culminate the episode using two additional discontinuities within the conversation. The first one is low- level because the appearance in v. 11 has many expected features. Firstly, it utilizes an expected S-P constituent structure with a grammaticalized

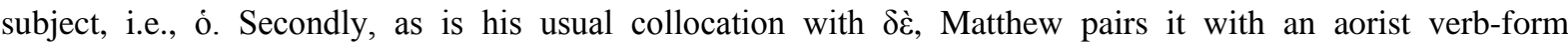
$\dot{\alpha} \pi$ кр $1 \theta \varepsilon i \mathrm{~s}$ that functions as the "background" choice for narrative. (Black, 2002: 117, 154; Porter, 1999: 23, 302) Lastly, much of what is fronted in the projected clause is not new information, but in fact repeats what the disciples have already asked for: that Elijah must come first. In setting up the coming mid-level discontinuity, however, the statement does instantiate three elements that leave the reader in expectation. The inclusion of $\mu \dot{\varepsilon} v$ which anticipates a corresponding $\delta \dot{\varepsilon}$ statement is the first clue. (Porter, 1999: 112; Black, 2002: 160) Next is changing the disciples' verb form from a background tense ( $\dot{\varepsilon} \lambda \theta \varepsilon \tilde{i} v)$ to a "foreground" one ("̌ $\rho \chi \varepsilon \tau \alpha$ ) and finally the future form of the newly submitted $\dot{\alpha} \pi$ oк $\alpha \tau \sigma \tau \eta \dot{\sigma} \sigma \varepsilon$ whose tense form semantically conveys "a higher degree 
of expectation for fulfillment.” (Porter, 1999: 45). The mid-level discontinuity is also what Matthew has Jesus use in his next statement: the pairing of a present tense form which itself is "foreground" tense $(\lambda \dot{\varepsilon} \gamma \omega)$ alongside a nongrammaticalized subject which is an unusual collocation with $\delta \dot{\varepsilon}$. Moreover, the statement includes many new items which, in an unexpected turn, are then directly connected to Jesus' fate (Black 2002: 173).

This transition comes by an unexpectedly clever switch of actor and process. The fronted participant, Jesus, is the actual recipient of the suffering. There are several reasons discussed in the next section that point to why this may be considered the culminating issue of the section. While using verbs that keep him in the active voice, the

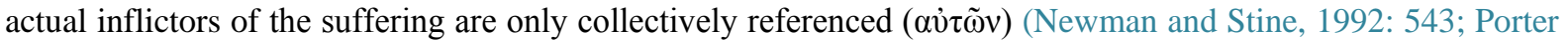
et al., 2006: Matt 17:12). Conjunctions help unveil the rhetoric involved here. The entire statement is a compar-

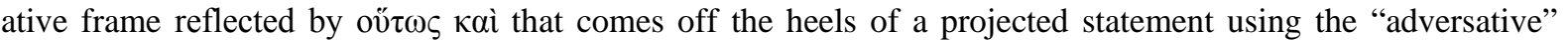

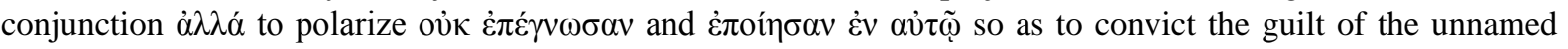
actors (Porter, 1999: 23, 205; Eriksson, 2002: 336).

\subsection{Aspectual Chain}

The markedness paradigm used by Porter helps solidify the cohesive flow of the section boundaries through aspectual contouring (Porter, 1999: 23, 303, 305; Porter and Brook O’Donnell, 2007: 8; Comrie, 1976: ch. 6; Basset, 2009: 205-220). See Table 5 below. This section identifies the prominent sections of discourse as signaled first according to aspectual theory, and then analyze how that section utilizes collocating features alongside aspect to accomplish this. Imperfective aspect according to Porter is realized in the Greek through two verbal tense forms: the present and the imperfect. $\varepsilon 1 \mu \mathrm{u}$ verbs are left out due to their "aspectually vague" status. Porter stresses this point: "Aspectually vague verbs may be used in any verbal context since they do not carry the semantic weight of perfective, imperfective or stative verbal aspect.” (Porter, 1999: 25; cf., Porter, 1989: ch. 10) emphasis original).

From an aspectual perspective, both v. 1 and v. 9 signal between "planes of discourse" which Porter has identified as one function of verbal aspect (Porter, 1999: 23). Each of these verses utilizes their own scene initiations through various means. Verse 1, for example, reinforces the aforementioned "point of departure" (Kaì $\mu \varepsilon \theta$ '

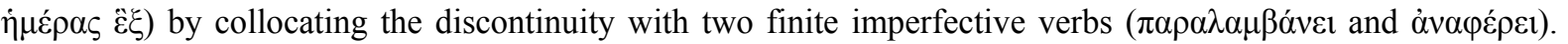

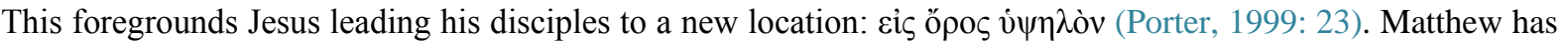
chosen a similar grammatical sequence for the break in v. 9 as well. Here he has chosen two imperfective as-

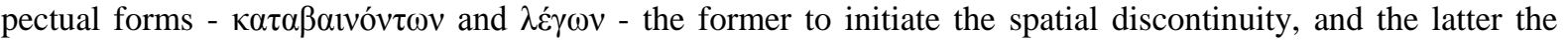
conversational one.

Moving deeper into the scene, two prominent "discourse peaks" materialize on the foundation of aspectual dis- tinctions, which fence off a "domain of prominence" at verses 5 and 12, the former an "action peak," the latter a "didactic peak.” (Reed, 1995: 81; Porter, 1999: 302; Longacre, 1999: 142, 156). Imperfective aspect ap-

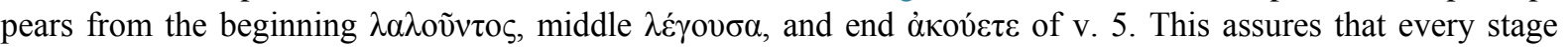
leading into this point of the narrative is received as cohesively bound within "foreground" material (Porter, 1999: 302). The next marked dimension to notice is the fact no participant at this point in the narrative receives explicit grammaticalization, though every one of the active participants for this episode is addressed. Indeed, apart from any presupposition, this entire verse would remain noninterpretable. This creates the highest level of

Table 5. Imperfective aspectual chain through Matt 17:1-13 (Porter, 1999: 21; idem, 1989: 92-93).

$$
\begin{aligned}
& \text { v. } 1 \pi \alpha \rho \alpha \lambda \alpha \mu \beta \alpha ́ v \varepsilon เ
\end{aligned}
$$

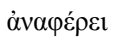

$$
\begin{aligned}
& \text { v. } 3 \sigma v \lambda \lambda \alpha \lambda \circ \tilde{v} \tau \tau \varepsilon \varsigma
\end{aligned}
$$

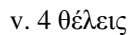

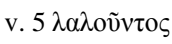

$$
\begin{aligned}
& \lambda \varepsilon ́ \gamma o v \sigma \alpha
\end{aligned}
$$

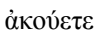$$
\text { v. } 7 \mu \grave{\varphi} \varphi \circ \beta \varepsilon \tilde{\sigma} \theta \varepsilon
$$

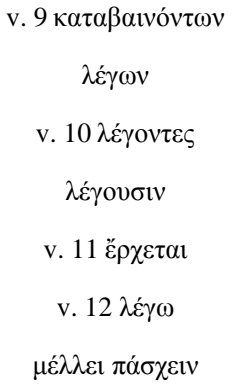


participant density in the entire episode and might be characterized as a kind of "4-way-stop" between all the chains discussed: Jesus, the supernatural, the disciples, and conjunctions.

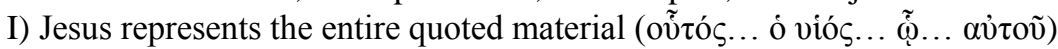

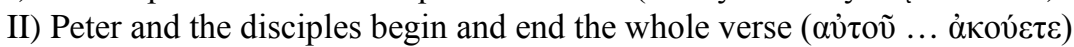

III) God the Father is referred to in a variety of ways

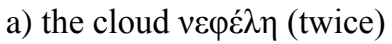

b) the voice $\varphi \omega v \eta$

c) the possessive pronoun $\mu \mathrm{ov}$

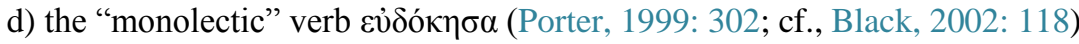

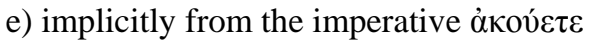

IV) Three internal instances of conjunction

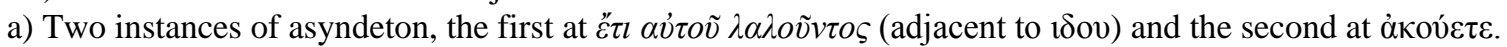

b) One instance of kaì $1 \delta o v$

The narrative returns to a chain of backgrounding aorist forms only to break at v. 7 with "have no fear" ( $\mu$ ì $\varphi \circ \beta \varepsilon i \tau \theta \varepsilon)$. Verse 8 concludes the action using Jesus within the complementing structure aforementioned.

The didactic peak of the section realizes similar climactic features to that of the action peak. Matthew fully

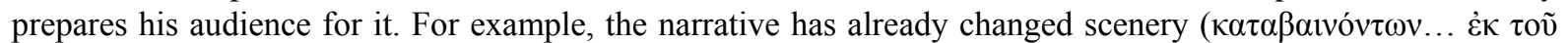

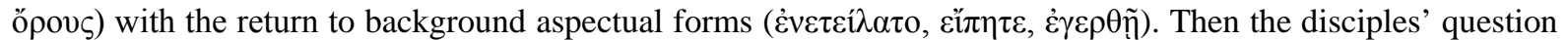
supplies Jesus with the material about Elijah which he ties back to and uses a $\mu \grave{\varepsilon} v \ldots \delta \dot{\varepsilon}$ format that concludes by culminating many cohesive ties with a dual foregrounding verbal aspect ( $\mu \varepsilon \dot{\varepsilon} \lambda \lambda \varepsilon 1 \pi \alpha ́ \sigma \chi \varepsilon เ v$ ). Notice once again, the full assumption of participants in the final clause of v. 12 similar to the discourse strategy of the action peak (Porter et al., 2006: Matt 17:12).

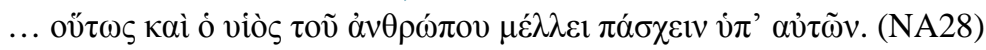

The fronted term ov๊ $\omega \varsigma$ assumes the entire previous statement of what happened to the Elijah figure which

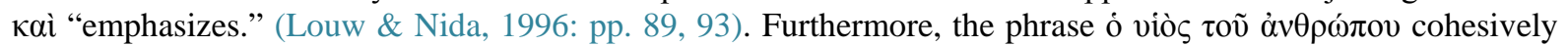
ties back to v. 6 modifying the syntax for the paradigmatic changes. The structure maps out the interpretive nature of the cohesive ties well. See Figure 4 below.

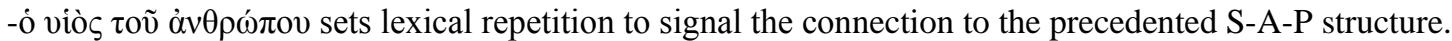

$-\mu \varepsilon \dot{\varepsilon} \lambda \varepsilon_{\varepsilon} \pi \alpha ́ \sigma \chi \varepsilon \mathrm{v}$ uses double-foregrounding in an overturn of the expected structural precedent which

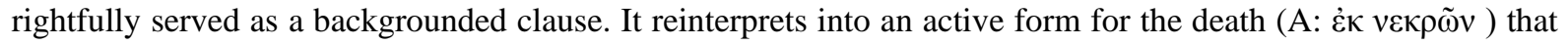

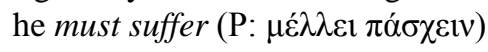

$-\dot{v} \pi$ ' $\alpha \hat{\tau} \tau \tilde{\omega} v$ recontextualizes the necessitated death in light of the new participants which are here assumed (oi $\gamma \rho \alpha \mu \mu \alpha \tau \varepsilon i \bar{c})$ as the ones causing the suffering. It also effectively contrasts the grammatically assumed agents of

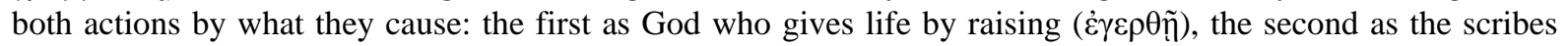
who take life through causing suffering ( $\pi \dot{\sigma} \sigma \chi \varepsilon t v)$.

-the syntagmatic switch not only justifies the strong foregrounding, but aids the audience to process the finality of the expository section by recalling the same syntagmatic switching strategy witnessed with the activity of the episode. (vv. 1, 8) This strategy is further corroborated by the same conjunction $\delta \varepsilon$ which is used to finalize each section. (cf., vv. 8, 12) This strategy of syntagmatic modification may be the impetus behind commentators' mistaken need to make a "chiasm” out of the material (Hagner, 1998: p. 491; Davies \&Allison, 2004: p. 684).

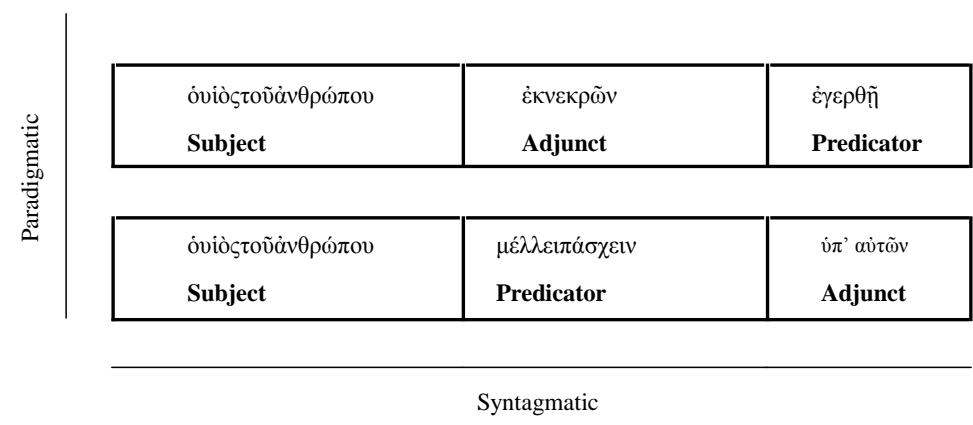

Figure 4. Structure Mapping Cohesion: parallel linguistic structure helps interpret cohesive ties (Porter et al., 2006: Matt 17:9, 12). 
It is only here at v. 13 that the distinctive Matthean way of "introducing the concluding ... speech to which an episode has been building up" is used, $\tau$ o $\varepsilon$ (Black, 2002: p. 247; cf., Porter, 1999: p. 217).

There Mathew's episode uses John the Baptist to close out both as a semantic tie for the expository section regarding Elijah's role, as well as a textual connection back to v. 1 differentiating between John the disciple and John the Baptist, while leaving his readers to conclude the unspo- ken rhetorical connection between Jesus and Moses as that connection to which all of the action and teaching seeks to demonstrate and cohere with the command to silence until the resurrection.

\section{Conclusion}

The linguistic study from a SFL perspective of cohesive ties and their respective chaining techniques represents a fundamental but singular component of a larger, fuller discourse analysis. This study has attempted to demonstrate the immanent value of using rigorous linguistic methodology toward the interpretation of scripture as any other human communication - as a register of speech which the author has used to reflect the situation within the context of that culture. Theological commentary simply will not deliver this. And the days of linguistic ambivalence have passed. This study has demonstrated the exegetical and interpretive benefits of committing to a specific linguistic framework. It follows a precedent set by modern biblical scholars for the methods required in comparative studies in the future, both inside and outside the biblical material, paving the way to unfold the greater context in which these documents are embedded.

\section{References}

Basset, L. (2009). The Use of the Imperfect to Express Completed States of Affairs: The Imperfect as a Marker of Narrative Cohesion. In S. Bakker, \& G. Wakker (Eds.), Discourse Cohesion in Ancient Greek (pp. 205-220). Leiden: Brill. http://dx.doi.org/10.1163/ej.9789004174726.i-284.61

Black, S.L. (2002). Sentence Conjunctions in the Gospel of Matthew: Kai, de, Tote, Gar, Syn and Asyndeton in Narrative Discourse (Volume 216). London: Sheffield Academic.

Blomberg, C. (1992). Matthew. NAC 22. Nashville: Broadman \& Holman.

Brown, A. (1989). Piggybook. London: Little Mammoth.

Comrie, B. (1976). Aspect (Cambridge Textbooks in Linguistics). Cambridge: Cambridge University.

Davies, W. D., and Allison Jr., D. C. (2004). A Critical and Exegetical Commentary on the Gospel According to Saint Matthew (Volume 2). ICC. New York: T\&T Clark.

Duling, D.C. (2012). A Marginal Scribe: Studies of the Gospel of Matthew in Social-Scientific Perspective (Matrix: The Bible in Mediterranean Context 7). Eugene, OR: Cascade Books.

Eriksson, Anders. (2002). Contrary Arguments in Paul's Letters. In S. E. Porter, \& D. Stamps (Eds.), Rhetorical Criticism and the Bible (pp. 336-354). JSNTS 195. London: Sheffield Academic.

Fawcett, R. P. (2000). A Theory of Syntax for Systemic Functional Linguistics. Amsterdam: Benjamins. http://dx.doi.org/10.1075/cilt.206

France, R. T. (2007). The Gospel of Matthew (NICNT). Grand Rapids, MI: Wm. B. Eerdmans.

Gledhill, C. (2009). Colligation and the Cohesive Function of Present and Past Tense in the Scientific Research Article. In D. Banks (Ed.), Les Temps et les Textes de Specialite (pp. 65-84). Paris: L’Harmattan.

Gregory, M. (1988). Generic Situation and Register: A Functional View of Communication. In J. D. Benson, \& W. S. Greaves (Eds.), Linguistics in a Systemic Perspective (pp. 301-330). Amsterdam: John Benjamins.

http://dx.doi.org/10.1075/cilt.39.12gre

Hagner, D. A. (1998). Matthew 14-28. WBC 33B, Dallas: Word.

Halliday, M. A. K. (1976). Anti-Languages. American Anthropologist, 78, 570-584.

http://dx.doi.org/10.1525/aa.1976.78.3.02a00050

Halliday, M. A. K. (1985). An Introduction to Functional Grammar (3rd ed.). London: E. Arnold.

Halliday, M. A. K. (2007). Language and Society. London: Continuum.

Halliday, M. A. K. (1978). Language as Social Semiotic: The Social Interpretation of Language and Meaning. London: Edward Arnold.

Halliday, M. A. K., \& Matthiessen, C. M. I. M. (2006). Construing Experience through Meaning: A Language-Based Approach to Cognition. Open Linguistics Series, London: Continuum. 
Halliday, M. A. K., \& Hasan, R. (1976). Cohesion in English. English Language Series, London: Longman.

Halliday, M. A. K., \& Hasan, R. (1989). Language, Context, and Text: Aspects of Language in a Social-Semiotic Perspective (2nd ed.). Oxford: Oxford University.

Hasan, R. (2009). The Place of Context in a Systemic Functional Model. In J. Webster, \& M. A. K. Halliday (Eds.), Continuum Companion to Systemic Functional Linguistics (pp. 166-189). London: Continuum.

Hasan, R. (1995). The Conception of Context in Text. In P. H. Fries, \& M. Gregory (Eds.), Discourse in Society: Systemic Functional Perspectives (pp. 183-284). Norwood, NJ: Ablex. http://dx.doi.org/10.1075/cilt.118

Hudson, R. A. (2001). Sociolinguistics (2nd ed.). Cambridge Textbooks in Linguistics, Cambridge: Cambridge University.

Keener, C. S. (2009). The Gospel of Matthew: A Socio-Rhetorical Commentary. Grand Rapids, MI: Wm. B. Eerdmans.

Kress, G. (1989). Linguistic Processes in Sociocultural Practice. Oxford: Oxford University.

Levinsohn, S. H. (1995). A Discourse Study of Constituent Order and the Article in Philippians. In S. E. Porter, \& D. A. Carson (Eds.), Discourse Analysis and Other Topics in Biblical Greek (pp. 60-74). JSNTS 113, Sheffield: Sheffield Academic.

Longacre, R. E. (1999). A Top-Down, Template-Driven Narrative Analysis, Illustrated by Application to Mark’s Gospel. In S. E. Porter, \& J. T. Reed (Eds.), Discourse Analysis and the New Testament: Approaches and Results (pp. 140-196). JSNTS 170, Sheffield: Sheffield Academic.

Louw, J. P., \& Nida, E. A. (1996). Greek-English Lexicon of the New Testament: Based on Semantic Domains (2 Vols.). New York: United Bible Societies.

Lukin, A., Moore, A. R., Herke, M., Wegener, R., \& Wu, C. Z. (2011). Halliday’s Model of Register Revisited and Explored. Linguistics and the Human Sciences, 4, 187-213. http://dx.doi.org/10.1558/lhs.v4i2.187

Luz, U. (2001). Matthew: A Commentary. Minneapolis, MN: Augsburg.

Martin, J. R. (2001). Cohesion and Texture. In D. Schiffrin, D. Tannen, \& H. E. Hamilton (Eds.), The Handbook of Discourse Analysis (pp. 35-53). Malden, MA: Blackwell.

Martin, J. R. (1992). English Text: System and Structure. Amsterdam: Benjamins. http://dx.doi.org/10.1075/z.59

Martin-Asensio, G. (2000). Transitivity-Based Foregrounding in the Acts of the Apostles: A Functional-Grammatical Approach to the Lukan Perspective. JSNTS 202, Sheffield: Sheffield Academic.

Martin, J. R., \& Rose, D. (2007). Working with Discourse: Meaning Beyond the Clause (2nd ed.). Open Linguistics Series, London: Bloomsbury.

Meeks, W. (1986). The Moral World of the First Christians. Library of Early Christianity 6, Philadelphia, PA: Westminster.

Metzger, B. M. (1994). A Textual Commentary on the Greek New Testament (2nd ed.). a Companion Volume to the United Bible Societies’ Greek New Testament (4th Rev. Ed.). New York: United Bible Societies.

Morley, J. (2009). Lexical Cohesion and Rhetorical Structure. In J. Flowerdew, \& M. Mahlberg (Eds.), Lexical Cohesion and Corpus Linguistics (pp. 5-22). Amsterdam: John Benjamins. http://dx.doi.org/10.1075/bct.17.02mor

Newman, B. M., \& Stine, P. C. (1992). A Handbook on the Gospel of Matthew. UBS Handbook Series, New York: United Bible Societies.

Nolland, J. (2005). The Gospel of Matthew: A Commentary on the Greek Text. NIGTC, Grand Rapids, MI: W.B. Eerdmans.

O’Donnell, M. B. (1999). Linguistic Fingerprints or Style by Numbers? The Use of Statistics in the Discussion of Authorship of New Testament Documents. In S. E. Porter, \& D. A. Carson (Eds.), Linguistics and the New Testament: Critical Junctures (pp. 206-255). JSNTS 168, Sheffield: Sheffield Academic.

Porter, S. E. (1999). Idioms of the Greek New Testament. Sheffield: JSOT.

Porter, S. E. (2004). The Criteria for Authenticity in Historical-Jesus Research: Previous Discussion and New Proposals. JSNTS 191, London: T \& T Clark.

Porter, S. E. (1989). Verbal Aspect in the Greek of the New Testament with Reference to Tense and Mood. New York: Peter Lang.

Porter, S. E., \& O’Donnell, M. B. (2007). Conjunctions, Clines and Levels of Discourse. Filologia Neotestamentaria, 20, 314.

Porter, S. E., O’Donnell, M. B., \& Reed, J. (2006). The OpenText.org Syntactically Analyzed Greek New Testament. Bellingham, WA: Logos Bible Software.

Puigdollers, A. R. R. (2009). The Particles AY and AYTE in Ancient Greek as Topicalizing Devices. In S. Bakker, \& G. Wakker (Eds.), Discourse Cohesion in Ancient Greek (pp. 83-110). Leiden: Brill.

Reed, J. T. (1999). The Cohesiveness of Discourse: Towards a Model of Linguistic Criteria for Analyzing New Testament Discourse. In S. E. Porter, \& J. T. Reed (Eds.), Discourse Analysis and the New Testament: Approaches and Results (pp. 28-46). JSNTS 170, Sheffield: Sheffield Academic. 
Reed, J. T. (1997). A Discourse Analysis of Philippians: Method and Rhetoric in the Debate over Literary Integrity. Sheffield: Sheffield Academic.

Reed, J. T. (1997). Discourse Analysis. In S. E. Porter (Ed.), Handbook to Exegesis of the New Testament (pp. 188-218). New Testament Tools and Studies 25, New York: Brill.

Reed, J. T. (1995). Identifying Theme in the New Testament: Insights from Discourse Analysis. In S. E. Porter, \& D. A. Carson (Eds.), Discourse Analysis and Other Topics in Biblical Greek (pp. 75-101). JSNTS 113, Sheffield: Sheffield Academic.

Reed, J. T. (2000). Language of Change and the Changing of Language: A Sociolinguistic Approach to Pauline Discourse. In S. E. Porter (Ed.), Diglossia and Other Topics in New Testament Linguistics (pp. 121-53). JSNTS 193, Sheffield: Sheffield Academic.

Rohrbaugh, R. L. (2007). The New Testament in Cross-Cultural Perspective/Matrix: The Bible in Mediterranean Context 1. Eugene, OR: Cascade Books.

Schiffrin, D. (1994). Approaches to Discourse. Blackwell Textbooks in Linguistics, Oxford: Blackwell.

Schmidt, F. (2001). How the Temple Thinks: Identity and Social Cohesion in Ancient Judaism. Sheffield: Sheffield Academic.

Stoddard, S. (1991). Text and Texture: Patterns of Cohesion. Norwood, NJ: Ablex.

Stubbs, M. (1983). Discourse Analysis: The Sociolinguistic Analysis of Natural Language. Language in Society 4, Chicago, IL: University of Chicago.

Teich, E. (2009). Linguistic Computing. In J. Webster, \& M. A. K. Halliday (Eds.), Continuum Companion to Systemic Functional Linguistics (pp. 113-127). London: Continuum.

Tucker, G. H. (1998). The Lexicogrammar of Adjectives: A Systemic Functional Approach to Lexis. Functional Descriptions of Language Series, London: Cassell.

Van Neste, R. (2004). Cohesion and Structure in the Pastoral Epistles. JSNTS 280, London: T \& T Clark International.

Woods, J. (2013). Antilanguage in the Synoptic Gospels: A Sociolinguistic Inquiry. Master's Thesis, Virginia Beach, VA: Regent University. 